\title{
Produção do conhecimento acerca da formação do enfermeiro: um estudo bibliométrico
}

\author{
Knowledge production about nurse education: a bibliometric study
}

Producción de conocimiento sobre la formación del enfermero: un estudio bibliométrico

\section{Margarete Maria de Lima', Alexsandro Barreto Almeida", Monica de Oliveira Giovannetti"', Vania Marli Schubert Backesiv ${ }^{\text {, Daiana Kloh }}{ }^{\mathrm{v}}$}

\author{
' Universidade Federal de Santa Catarina, Programa de Pós-Graduação em Enfermagem (Mestranda), \\ Grupo de Pesquisa em Educação em Enfermagem. Florianópolis-SC, Brasil. \\ "Faculdade Estácio de Sá, Curso de Enfermagem. São José-SC, Brasil. \\ II' Universidade Federal de Santa Catarina, Programa de Pós-Graduação em Enfermagem (Mestranda). \\ Florianópolis-SC, Brasil. \\ Iv Universidade Federal de Santa Catarina, Programa de Pós-Graduação em Enfermagem, \\ Grupo de Pesquisa em Educação em Enfermagem. Florianópolis-SC, Brasil. \\ $\checkmark$ Universidade Federal de Santa Catarina, Curso de Enfermagem (Graduanda), \\ Grupo de Pesquisa em Educação em Enfermagem. Florianópolis-SC, Brasil.
}

Submissão: 15-07-2010 Aprovação: 30-07-2012

\section{RESUMO}

Este estudo busca identificar as produções de teses e dissertações de enfermagem catalogadas no Centro de Estudos e Pesquisas em Enfermagem - CEPEN, que abordem a formação do enfermeiro considerando as Diretrizes Curriculares Nacionais na perspectiva da formação para o SUS. Estudo bibliométrico e descritivo realizado no CEPEN nos catálogos de 2003 a 2007. Foram selecionados 27 trabalhos, analisados quantitativamente quanto à instituição de ensino, ano de publicação, titulação da pesquisa (dissertação ou tese), tipo de pesquisa, e, qualitativamente os temas e referencial teórico filosófico e metodológico. Os resultados evidenciam $100 \%$ dos trabalhos desenvolvidos em instituições públicas, com uma produção maior em teses; há poucos estudos que tratam do perfil do egresso, bem como da formação para o SUS.

Descritores: Enfermagem; Ensino; Sistema Único de Saúde.

\section{ABSTRACT}

This study aims to identify the nursing theses and dissertation production catalogued in the Center for Study in Nursing Research - CEPEN, which treats nurse formation according to the National Curricular Directives on the SUS formation approach. This is a bibliometric and descriptive study performed on the theses and dissertations catalog of CEPEN, between 2003 and 2007. Twenty seven papers were selected, and quantitatively analyzed according to institution, year of publication, degree of research (dissertations or theses), type of research, and qualitatively analyzed according to themes, philosophical theory, and methodological reference. The results show $100 \%$ of the work performed in public institutions, with increased production in theses, there are few studies that deal with the profile of graduates, as well as training for SUS.

Key words: Nursing; Teaching; Single Health System.

\section{RESUMEN}

Este estudio intenta identificar las pesquisas de enfermería catalogadas en el Centro de Estudios y Pesquisas de Enfermería CEPEN, que aborden la formación de enfermero considerando las Directrices Curriculares Nacionales con la perspectiva de la formación para el SUS. Estudio bibliométrico y descriptivo de los catálogos del 2003 al 2007 del CEPEN, siendo seleccionados 27 trabajos, analizados cuantitativamente en cuanto a la institución de enseñanza, año de publicación, titulación de la pesquisa (disertación o tesis), tipo de pesquisa y, cualitativamente los temas y referencial teórico, filosófico y metodológico. Los resultados muestran que el $100 \%$ de los trabajos realizados en las instituciones públicas, con el aumento de la producción de tesis, son pocos los estudios que abordan el perfil de los egresados, así como la capacitación para él SUS.

Palabras clave: Enfermería; Enseñanza; Sistema Único de Salud. 


\section{INTRODUÇÃO}

A Reforma Sanitária Brasileira iniciada no final dos anos 1970 ocorreu como resposta à insatisfação e descontentamento existente entre profissionais da saúde, trabalhadores, donas de casa e usuários dos serviços públicos de saúde em geral, em relação aos direitos de cidadania, acesso, serviços e forma de organização do sistema de saúde brasileiro e se concretizou a partir da organização do chamado "movimento sanitário" e de uma produção significativa de estudos e pesquisas no campo das políticas de saúde que indicavam as relações entre saúde e estrutura social ${ }^{(1-2)}$.

No início dos anos 1980 se desenvolveram as chamadas Ações Integradas de Saúde - AIS, o primeiro desenho estratégico de cogestão, de desconcentração e de universalização da atenção à saúde. Em meados dessa mesma década realizou-se a VIII Conferência Nacional de Saúde, marco da luta pela reforma da saúde, que levou à criação do SUS $S^{(1-2)}$.

O SUS é, portanto um produto da Reforma Sanitária Brasileira e foi criado pela Constituição da República Federativa do Brasil de 1988 incorporando, parcialmente, as propostas estabelecidas por esse movimento definindo a saúde como um direito social, cuja garantia é responsabilidade do Estado, assegurado mediante duas condições básicas: políticas públicas econômicas e sociais, e acesso a todos os brasileiros a serviços e ações de saúde ${ }^{(1-2)}$.

Dentre as mudanças ocorridas no setor de saúde está a responsabilidade do SUS no ordenamento da formação de recursos humanos da área. Destacam-se também a construção social contínua exigida pelo sistema e as mudanças de paradigmas do processo saúde-doença ${ }^{(3)}$, entendendo a saúde como um processo complexo, produto da história de vida, da cultura, do social e econômico, das condições de vida e trabalho, da subjetividade, dos valores, desejos e das relações afetivas das pessoas e da coletividade.

Com a implantação do SUS há uma expansão do mercado de trabalho em saúde coletiva iniciando-se o diálogo entre várias disciplinas com o objetivo da produção de conhecimento sendo, no entanto, necessário inventar novas práticas em saúde, que superem as ações fragmentadas do modelo biomédico ainda tão enraizadas ${ }^{(4)}$.

A formação dos profissionais de saúde deve, portanto, estar orientada para atender estas mudanças paradigmáticas, tendo como foco o cuidado centrado no sujeito enquanto ser histórico e social, percebido em sua integralidade e ativo no processo de saúde-doença. É preciso também considerar "a importância de um projeto político-pedagógico para sustentar a formação profissional"(5).

Desta forma as Diretrizes Curriculares dos Cursos de Graduação da área da saúde ${ }^{(2)}$ - as quais se constituem nas orientações para construção dos currículos a serem obrigatoriamente adotadas pelas instituições de ensino superior - foram formuladas no ano de 2001, estabelecendo o conceito de saúde, os princípios e diretrizes do SUS como elementos fundamentais na construção da articulação entre Educação Superior e Saúde. Tais Diretrizes passaram a ter como objeto:
Permitir que os currículos propostos possam construir perfil acadêmico e profissional com competências, habilidades e conteúdos, dentro de perspectivas e abordagens contemporâneas de formação pertinentes e compatíveis com referencias nacionais e internacionais, capazes de atuar com qualidade, eficiência e resolutividade, no Sistema Único de Saúde (SUS), considerando o processo da Reforma Sanitária Brasileira ${ }^{(6)}$.

A formação e a educação em saúde, ao longo dos últimos anos e no contexto da reforma sanitária intensificaram movimentos voltados para a construção de outras possibilidades pedagógicas que impulsionaram propostas de mudança na formação ${ }^{(7)}$. As diretrizes Curriculares Nacionais correspondendo a esta nova realidade estabelecem ainda como objetivos:

Levar os alunos dos cursos de graduação em saúde a aprender a aprender que engloba aprender a ser, aprender a fazer, aprender a viver juntos e aprender a conhecer, garantindo a capacitação de profissionais com autonomia e discernimento para assegurar a integralidade da atenção e a qualidade e humanização do atendimento prestado aos indivíduos, famílias e comunidades ${ }^{(6)}$.

Nessa perspectiva, o presente estudo, busca identificar as produções de teses e dissertações de enfermagem catalogadas no Centro de Estudos e Pesquisas em Enfermagem que abordem a formação do enfermeiro, considerando as Diretrizes Curriculares Nacionais na perspectiva da formação para o SUS.

Nesse sentido, este estudo parte do entendimento que a formação para o SUS fundamenta o processo de educação superior através do desenvolvimento de competências e habilidades, a partir da flexibilização dos currículos conforme a realidade local e regional e da implementação de Projetos Políticos Pedagógicos criativos e norteados nos princípios do SUS. Essa premissa aponta novas configurações para os padrões curriculares, até então vigentes, indicando a necessidade de uma reestruturação dos cursos de graduação com mudanças paradigmáticas no contexto da comunidade acadêmica e sociedade.

\section{METODOLOGIA}

Trata-se de um estudo bibliométrico e descritivo, realizado no catálogo de Teses e Dissertações do Centro de Estudos e Pesquisas em Enfermagem - CEPEn. A bibliometria permite a quantificação de comunicação escrita(8). A base de dados CEPEn está disponível online, é o maior banco de teses e dissertações em enfermagem do Brasil.

A seleção das publicações catalogadas foi feita mediante critérios de inclusão e exclusão. Assim selecionaram-se os trabalhos que abordavam formação de enfermagem para o Sistema Único de Saúde, Diretrizes Curriculares Nacionais de enfermagem e Projeto Político Pedagógico. A pesquisa compreendeu os catálogos de 2003 a 2007, este critério de inclusão do ano inicial é devido à aprovação das diretrizes curriculares nacionais em 2001. Os critérios de exclusão foram trabalhos que não apresentavam enfoque na formação ou aderência aos temas pesquisados. 
Uma primeira seleção foi realizada através da leitura dos títulos e, posteriormente, a partir dos resumos e nos trabalhos completos as informações para a categorização. Elaborou-se uma ficha de catalogação para coleta de dados contendo os seguintes dados bibliométricos: tema do trabalho, autor, instituição de ensino, ano de publicação, titulação da pesquisa (dissertação ou tese), tipo de pesquisa, referencial teórico filosófico e metodológico. Após leitura e fichamento das publicações, analisaram-se qualitativamente os dados referentes ao tema e referencial teórico, sendo estes classificados em categorias temáticas. Os demais dados foram analisados quantitativamente.

\section{RESULTADOS E DISCUSSÃO}

Foram encontrados nos catálogos 2.218 resumos de trabalhos, entre os quais 1.618 dissertações (73\%) e 600 teses $(27 \%)$, sendo selecionadas 27 pesquisas que atendiam ao critério de inclusão previamente estabelecido. Os resultados foram agrupados em forma de tabela para melhor visualização e compreensão. Quanto ao ano de publicação do trabalho no catálogo do CEPEn, encontramos maior freqüência no ano de 2006 (33,33\%), seguido de 2004 (25,92\%), em 2005 (22,22\%), em $2007(14,81 \%)$ e $2003(3,73 \%)$. Estes resultados podem estar evidenciando uma maior preocupação e interesse no tema a partir da homologação em 2001 das Diretrizes Curriculares Nacionais e a consequente alteração nos currículos.

Quanto à característica da produção evidenciou-se maioria em teses $(55,55 \%)$ e $(44,45 \%)$ em dissertações As dissertações e teses defendidas representam cinco instituições de ensino superior, todas públicas, demonstrando o interesse destas escolas em pesquisar temáticas relacionadas à qualidade da formação do enfermeiro, bem como, evidenciando que é na escola pública onde ocorre maior desenvolvimento de pesquisas e produção do conhecimento científico. Sendo uma destas instituições divididas em duas escolas de enfermagem, localizadas em municípios diferentes, São Paulo e Ribeirão Preto. Houve um predomínio de pesquisas desenvolvidas na região sudeste. A tabela 01 apresenta os trabalhos de acordo com a região e instituição de defesa.

Quanto à modalidade da pesquisa, verificou-se predomínio de estudos qualitativos (89\%), quantitativos (7\%) e quanti-qualitativos (4\%). Esse resultado dá subsidio para a prática de enfermagem na formação, pois esta lida com a vida das pessoas, com a subjetividade, crenças, valores e atitudes. A investigação qualitativa ${ }^{(9)}$ trabalha com representações, opiniões, hábitos, aprofundando a complexidade de fatos sejam eles individuais ou coletivos. A tabela 04 apresenta a modalidade de pesquisa encontrada nos estudos.

Quanto à coleta de dados observou-se que a entrevista (aberta ou semiestruturada) é a técnica mais utilizada sendo referida em 19 dos 27 estudos selecionados. A pesquisa ou análise documental foi utilizada em quatro trabalhos; um utilizou o método da pesquisa participativa, dois o método da pesquisa-ação e quatro realizaram grupo focal, cabendo salientar que em alguns dos estudos analisados foram utilizadas mais de uma técnica de coleta de dados. Foram encontrados quatro estudos de caso e um estudo cuja trajetória metodológica foi baseada na Teoria Fundamentada nos Dados.

Dos 27 trabalhos selecionados um tratava-se de pesquisa do tipo quali-quantitativa, um de pesquisa descritiva transversal e outro de quantitativa não experimental do tipo survey.

Quanto à análise e interpretação dos dados um trabalho referiu ter utilizado a metodologia hermenêutica dialética, três adotaram a análise de conteúdo de Bardin e dois a análise do discurso de Fiorin. Um estudo referiu basear-se no Modelo de Avaliação Emancipatória de Saul e um na Teoria da Ação Comunicativa de Habermas.

Para a categorização dos temas selecionados utilizou-se como critérios os tópicos elencados nas Diretrizes Curriculares Nacionais dos Cursos de Graduação em Enfermagem, a saber: Perfil do Formando Egresso/Profissional; Competências e Habilidades Gerais e Específicas; Conteúdos Curriculares; Estágios e Atividades Complementares; Organização do Curso; e Acompanhamento e Avaliação.

Assim identificou-se que seis estudos se dedicaram a investigar a questão das Competências e Habilidades, sendo que, dois destes abordaram as competências gerais do egresso; um tratou especificamente da competência para a Atenção à saúde; dois para a Administração e gerenciamento e um abordou a competência específica para a interdisciplinaridade. A tabela 02 apresenta as fragilidades e potencialidades encontradas nos resultados dos estudos.

Tabela 01 - Regiões e instituições mais representadas nas dissertações e teses.

\begin{tabular}{llcc}
\hline Região & \multicolumn{1}{c}{ Instituição } & No de trabalhos & \% \\
\hline Sul & Universidade Federal de Santa Catarina & 03 & 11,11 \\
& Universidade de São Paulo/Ribeirão Preto & 10 & 37,04 \\
& Universidade de São Paulo/SP & 09 & 33,33 \\
Sudeste & Universidade Federal de São Paulo & 01 & 3,70 \\
& Universidade Federal de Minas Gerais & 02 & 7,41 \\
Nordeste & Universidade Federal da Paraíba & 02 & 7,41 \\
\hline Total & & 27 & 100 \\
\hline
\end{tabular}


Tabela 02 - Estudos que abordaram as competências e habilidades.

\begin{tabular}{|c|c|}
\hline Autor/orientador & Resultados \\
\hline $\begin{array}{l}\text { Alexandre, LBSP/ } \\
\text { Oliveira, EM }\end{array}$ & $\begin{array}{l}\text { Nas universidades públicas há busca por "status quo" da educação e da prática de saúde, porém, a mesmas lidam com } \\
\text { a dificuldade de concretizar ou alcançar parcialmente os conteúdos propostos em seus projetos pedagógicos. Tanto nas } \\
\text { universidades públicas como nas privadas ocorre uma formação para o exercício da regulamentação e não emancipação. }\end{array}$ \\
\hline $\begin{array}{l}\text { Gabrielli, JMW/ } \\
\text { Pela, NTR }\end{array}$ & $\begin{array}{l}\text { Processo formativo desvinculado da prática profissional, gerando descompasso entre o aprendido e o vivenciado; for- } \\
\text { mação de profissional crítico, reflexivo, capaz de atuar e promover mudanças na realidade continua apenas no discurso; } \\
\text { as reformas curriculares têm levado apenas a alterações de aspectos pontuais. }\end{array}$ \\
\hline $\begin{array}{l}\text { Gattás, MLB/ } \\
\text { Furegato, ARF }\end{array}$ & $\begin{array}{l}\text { A interdisciplinaridade tem componente de ordem subjetiva representado pela vontade de cooperação, colaboração, } \\
\text { diálogo, abertura do conhecimento para o outro e realização de trabalho comum. Envolve questões de atitudes frente à } \\
\text { construção do conhecimento, sua compreensão e sua práxis }\end{array}$ \\
\hline $\begin{array}{l}\text { Resck, ZMR/ } \\
\text { Gomes, ELR }\end{array}$ & $\begin{array}{l}\text { Para a conformação de competências gerenciais é necessário fortalecer parceria ensino e serviço no âmbito inter- } \\
\text { institucional, criar uma rede de sustentação, aproximando os profissionais, os usuários/clientes, construindo no coletivo a } \\
\text { formação e a práxis, voltadas para as demandas sociais e da vida. }\end{array}$ \\
\hline $\begin{array}{l}\text { Peres, AM/ } \\
\text { Ciampone, MHT }\end{array}$ & $\begin{array}{l}\text { Os resultados apontam a necessidade de o ensino estreitar as relações com o mercado de trabalho no sentido de ampliar } \\
\text { a valorização das competências gerenciais do enfermeiro para além da dimensão técnica, contemplando estas dimensões: } \\
\text { comunicativa, ética, política e de desenvolvimento da cidadania. }\end{array}$ \\
\hline $\begin{array}{l}\text { Machado, VB/ } \\
\text { Kurcgant, P }\end{array}$ & $\begin{array}{l}\text { Os docentes consideram importantes competências técnico-cientifica, ético, política, gerencial, relacional/afetiva, desen- } \\
\text { volvimento do pensamento critico. Necessidade de capacitação docente para atender as exigências das Diretrizes Curricu- } \\
\text { lares Nacionais e Projeto Político Pedagógico. Necessidade de vivências de construção coletiva para o desenvolvimento } \\
\text { de suas competências. }\end{array}$ \\
\hline
\end{tabular}

Os estudos evidenciam que apesar dos avanços ocorridos com as Diretrizes curriculares Nacionais, ainda tem-se um longo caminho a trilhar na busca de uma formação que atenda as necessidades das realidades encontradas. Com o desenvolvimento de competências e habilidades desenvolvidas nas graduações espera-se que o egresso "tenha capacidade de utilizar uma diversidade de conhecimentos na solução de problemas do seu dia-a-dia, estabelecendo relações entre cultura, sociedade, ética e educação". Pensar em competências significa articular vários conhecimentos na resolução de problemas e no enfrentamento de situações inesperadas, como também mobilizar a inteligência frente aos desafios do trabalho(7).

Os Conteúdos Curriculares conforme tabela 03, foram tratados em seis estudos, sendo todos na área das Ciências da Enfermagem: um abordou Fundamentos de enfermagem; um

Tabela 03 - Abordagem das fragilidades e potencialidade dos conteúdos curriculares.

\begin{tabular}{l|l}
\hline $\begin{array}{l}\text { Autor/ } \\
\text { Orientador(s) }\end{array}$ & \multicolumn{1}{c}{ Resultados } \\
\hline $\begin{array}{l}\text { Valsecchi, EASS/ } \\
\text { Nogueira, MS }\end{array}$ & $\begin{array}{l}\text { Evidencia semelhanças e disparidades no desenvolvimento do processo ensino-aprendizagem na disciplina de fundamen- } \\
\text { tos de enfermagem, necessitando de organização. }\end{array}$ \\
\hline $\begin{array}{l}\text { Cunha, AZS/ } \\
\text { Ramos, FRS }\end{array}$ & $\begin{array}{l}\text { Criação de um espaço de negociação entre os sujeitos envolvidos com o processo formativo com o objetivo de aprimorar } \\
\text { e consolidar uma filosofia de trabalho no curso. O egresso de enfermagem está atendendo às necessidades da região de } \\
\text { pesquisa na área. }\end{array}$ \\
\hline $\begin{array}{l}\text { Franqueiro, NVJ/ } \\
\text { Mendes, MMR }\end{array}$ & $\begin{array}{l}\text { Fragilidade na formação de docentes responsáveis pelo ensino do cuidado a idosos; o projeto pedagógico ainda que } \\
\text { esteja em conformidade com as Diretrizes Curriculares Nacionais para formar enfermeiros críticos, não dá visibilidade ao } \\
\text { ciclo vital como eixo integrador da formação profissional. }\end{array}$ \\
\hline $\begin{array}{l}\text { Maftum MA/ } \\
\text { Alencastre, MB }\end{array}$ & $\begin{array}{l}\text { A morosidade na efetiva implantação do Programa de Saúde Mental acarreta entraves nas transformações da formação } \\
\text { dos enfermeiros que vão atuar na área, devido à escassez ou até a inexistência de serviços em sistema de rede para a } \\
\text { realização da prática do futuro profissional. }\end{array}$ \\
\hline $\begin{array}{l}\text { Almeida, DV/ } \\
\text { Chaves, EC }\end{array}$ & $\begin{array}{l}\text { Das ementas investigadas 59\% apresentaram algum termo relacionado à humanização, revelando a intenção das Insti- } \\
\text { tuições Ensino Superior em ensinar o tema. No entanto, ao averiguar a consistência de tais conteúdos, apenas uma das } \\
\text { instituições poderia proporcionar o ensino da humanização através de duas disciplinas interligadas. }\end{array}$ \\
\hline $\begin{array}{l}\text { Falcón GCS/ } \\
\text { Erdmann, AL }\end{array}$ & $\begin{array}{l}\text { O aluno compreende a complexidade da saúde e sua inter-relação com a sociedade e o meio-ambiente e procura pos- } \\
\text { sibilidades para a atuação de enfermagem na promoção da saúde - construindo o ensinar e aprender na ordem, desordem } \\
\text { e auto-organização para uma nova forma de cuidar promovendo a saúde. }\end{array}$ \\
\hline
\end{tabular}


voltou-se para o Ensino de Enfermagem e quatro trataram da questão da Assistência de Enfermagem englobando conteúdos em gerontologia, saúde mental, humanização e promoção da saúde.

A questão do Acompanhamento e Avaliação dos alunos, do processo ensino-aprendizagem e dos próprios cursos de graduação foi tratada em cinco trabalhados, sendo que dois trataram da Avaliação do curso; dois da competência docente e um buscou a avaliação da formação do enfermeiro na percepção do egresso. O Processo de avaliação(10) tem sido discutido na formação, sendo que, muitos autores apontam vários caminhos, surgindo diferentes propostas. Estas estratégias devem favorecer ao aluno insights sobre seu próprio processo educacional, informando "alunos e professores sobre a qualidade da experiência educacional". A avaliação deve ser reconhecida como integrante do processo de formação e não como um fim em si mesmo, contribuindo para a formação de sujeitos éticos com capacidade de fazer escolhas ao longo da vida.

Foram identificados quatro trabalhos que versaram sobre a questão da Organização do Curso no que diz respeito à pesquisa; a mudança curricular, a elaboração de projeto político pedagógico e às abordagens pedagógicas. Na construção ${ }^{(11)}$ de projetos políticos pedagógicos é fundamental que ocorra discussão e reflexão entre todos os atores envolvidos no processo de formação acerca das transformações que estão ocorrendo no mundo do trabalho e no setor saúde. Os projetos devem ser reflexos das necessidades de saúde da clientela e das competências profissionais construídas cotidianamente.

Os Estágios (curriculares e extracurriculares) foram tema de quatro dos estudos selecionados; e, finalmente, o Perfil do egresso foi a preocupação de dois trabalhos, sendo que um tratou da questão da integralidade e outro das expectativas de docentes e discentes quanto a esse princípio do SUS. A tabela 04 apresenta os resultados de estudos que abordam esta categoria.

Atualmente os campos de práticas ocorrem em ambulatórios, unidades básicas, comunidades e domicílios contrapondo o que ocorria em outras décadas, onde as práticas eram centradas nos hospitais. Os cenários de práticas devem ser diversificados agregando equipamentos de saúde, educacionais e comunitários. A integração dos acadêmicos com os cenários de prática deve ocorrer no início do curso, aproximando-os da população e demais profissionais, prestando cuidados gradativos ao seu nível de formação e autonomia e, de acordo com a realidade encontrada ${ }^{(12)}$. Estes espaços de prática e estágios são "ricos em situações concretas, frente a situações limites onde o enfermeiro possa desenvolver seu compromisso ético-profissional, possibilitando-lhes desenvolverem a análise crítica dos direitos e responsabilidades profissionais [...]"(13)

Cabe ressaltar que dentre as categorias elaboradas evidencia-se semelhança em alguns resultados relacionados às competências e habilidades (22\%) com conteúdos curriculares $(22 \%)$, organização do curso $(15 \%)$ e estágios $(15 \%)$. Outro dado que chama a atenção é relacionado à pequena quantidade de pesquisas que abordem o perfil do egresso (07\%), pois este é objeto das Diretrizes Curriculares necessitando de estudos que comprovem a formação do enfermeiro com o perfil desejado nas diretrizes. Transpor o que determina as novas leis da educação à formação do enfermeiro é o grande desafio da atualidade na área da enfermagem "ao formar profissionais que superem o domínio teórico-prático exigido pelo mercado de trabalho, enquanto agentes inovadores e transformadores do mundo do trabalho" ${ }^{\prime \prime}(3)$

No que diz respeito à fundamentação teórico-filosófica identificou-se que dentre os 27 trabalhos (teses e dissertações) selecionados e analisados sete não trazem o referencial teórico-filosófico claramente definido. Três destes trabalhos têm como referência a Política Nacional de Educação, Lei de Diretrizes e Bases, Diretrizes Curriculares Nacionais em Enfermagem; um quarto trata do ensino de enfermagem em saúde mental e o processo de reforma psiquiátrica; outro versa sobre o Programa Pró-Saúde. Ainda dentre os que não trazem referencial teórico-filosófico explicitado, dois discutem o conceito de competência, sendo que um deles trata de pesquisa quanti-qualitativa.

Dentre os trabalhos que possuem referencial teórico, identificou-se um que aborda também o conceito de competência sobre a ótica da interpretação hermenêutica-dialética como referência teórica. Foram encontrados cinco estudos que utilizam o materialismo histórico-dialético ou a hermenêutica dialética como base teórico-filosófica; e, ainda, outros quatro trabalhos, têm também como base a filosofia marxista: um

Tabela 04 - Resultado dos estudos que abordam estágios curriculares e extracurriculares.

\begin{tabular}{l|l}
\hline Autor/ Orientador(s) & Resultados \\
\hline $\begin{array}{l}\text { Ito, EE/ } \\
\text { Takahashi, RT }\end{array}$ & $\begin{array}{l}\text { Identifica-se o reconhecimento do enfermeiro assistencial no seu papel de enfermeiro educador e que considera as } \\
\text { contribuições dos alunos no campo da prática como positivas e influentes no trabalho do setor. }\end{array}$ \\
\hline $\begin{array}{l}\text { Santos, MSS/ } \\
\text { Mendes, IAC }\end{array}$ & $\begin{array}{l}\text { O estágio Extracurricular oportuniza a elaboração de uma práxis que, no retorno à Universidade, docentes e discentes } \\
\text { trarão um aprendizado submetido à reflexão teórica que acrescentará no conhecimento já existente. }\end{array}$ \\
\hline $\begin{array}{l}\text { Koeche DK/ } \\
\text { Reibnitz, KS }\end{array}$ & $\begin{array}{l}\text { Quanto aos estágios curriculares supervisionados e os seus propósitos, precisa ser de domínio de todos os sujeitos } \\
\text { envolvidos no processo afim de que, ocorra uma efetiva integração entre o mundo da escola e o mundo do trabalho. }\end{array}$ \\
\hline $\begin{array}{l}\text { Pires, RP/ } \\
\text { Ciampone, MHT }\end{array}$ & $\begin{array}{l}\text { competências relacionais e atitudinais. Os estagiários ingressam no estágio extracurricular buscando competências no } \\
\text { aprender a conhecer e aprender a fazer, mas atribuem maiores ganhos nas competências do aprender a viver juntos } \\
\text { e aprender a ser. }\end{array}$
\end{tabular}


que se apóia na teoria crítica (Maclaren, Saupe, Nietzsche e Libâneo), um na sociologia reflexiva de Bourdieu, um na Teoria da Intervenção Práxica da Enfermagem em Saúde Coletiva - TIPESC e outro na Filosofia da Práxis de Adolfo Sanchez Vásquez.

Foram identificados três trabalhos ancorados na fenomenologia, sendo um baseado em Heidegger e dois em Alfred Schutz, e, cinco com diferentes abordagens: um baseado nos conceitos de mudança de paradigma de Santos, um embasado na Teoria Geral dos Sistemas (Bertalanffy), um na Abordagem humanista, um na Teoria da Complexidade e outro na classificação das abordagens pedagógicas propostas por José Carlos Libâneo.

Por fim havia duas pesquisas que, ao utilizarem a metodologia quantitativa, não trouxeram referencial teórico-filosófico.

\section{CONSIDERAÇÕES FINAIS}

Este estudo bibliométrico relacionado à formação do enfermeiro é fonte de informação que poderá auxiliar pesquisadores e comunidade acadêmica a refletir sobre a formação do enfermeiro e a necessidade de maior produção de pesquisas neste campo.

O Banco de dados do CEPEn é um recurso que contribui para identificar as pesquisas produzidas na área da enfermagem no Brasil permitindo fácil acesso às informações a partir de catalogações anuais das produções relacionadas à área de enfermagem.

O levantamento realizado nos catálogos de Teses e Dissertações do Centro de Estudos e Pesquisas em Enfermagem entre os anos de 2003 a 2007 aponta um resultado inexpressivo de pesquisas acerca da formação do enfermeiro, ou seja,
27 trabalhos sobre o tema em 2218 pesquisas encontradas, correspondendo a $1,21 \%$ do total dos trabalhos catalogados. Tal resultado indica a necessidade de ampliação dos estudos neste campo por tratar-se de um tema prioritário no sentido de que a qualidade do ensino, baseado nos princípios do SUS, irá refletir na sólida formação do profissional e, consequentemente, na qualidade da assistência e no processo de efetivação de um sistema público de saúde que atenda efetivamente as necessidades da população.

Os grupos de pesquisas em educação e enfermagem são celeiros para as pesquisas voltadas ao ensino. Um estudo (14) realizado nos grupos de pesquisa da região Sul do Brasil, apresenta um percentual de $59 \%$ de instituições públicas que possuem grupos de pesquisa em educação em enfermagem contra $12 \%$ nas instituições privadas, evidenciando um número ainda pequeno de instituições que se dedicam a pesquisar na nesta área. Tais dados servem de ponto de partida para despertar a reflexão de pesquisadores e integrantes dos grupos de pesquisa de educação em enfermagem para que busquem mecanismo que fortifiquem a integração, a produção, o crescimento e desenvolvimento de todos os integrantes dos grupos de pesquisas.

Verificou-se, no entanto que poucos estudos enfocam especificamente a formação para o SUS e também uma pequena parcela $(7 \%)$ que aborda o perfil dos egressos, necessitando de estudos que avaliem a formação de acordo com o perfil do enfermeiro pautado nas Diretrizes Curriculares Nacionais. Havendo em contrapartida uma maior preocupação em avaliar as questões relacionadas aos conteúdos curriculares e as competências dos diversos atores do processo de ensino-aprendizagem, quais sejam docentes, discentes e profissionais assistenciais ou com responsabilidade de gerenciamento.

\section{REFERÊNCIAS}

1. Faleiros VP; SILVA JFS.; Vasconcellos, LCF; Silveira RMG. A Construção do SUS: Histórias da Reforma Sanitária e do Processo Participativo. Brasília: Ministério da Saúde; 2006.

2. Gallo E, Luchesi G, Filho NM, Ribeiro PT. Reforma Sanitária: uma análise de viabilidade. Cad Saúde Pública 1988;4(4):414-9.

3. ITO, E. E. O ensino de enfermagem e as diretrizes curriculares nacionais: utopia x realidade. Rev Esc Enferm USP 2006;40(4):570-5.

4. Ceccim RB. Educação Permanente em Saúde: desafio ambicioso e necessário. Interface Comun Saúde Educ 2004/2005;9(16):161-77.

5. Reibnitz KS, Prado ML. Formação do profissional crítico-criativo: a investigação como atitude de (re)conhecimento do mundo. Texto \& Contexto Enferm 2003;12(1):26-33.

6. Conselho Nacional de Educação Câmara da Educação
Superior (Brasil). Parecer $\mathrm{n}^{\circ} 1.133$, de 7 de agosto de 2001. Dispõe sobre as diretrizes curriculares da Medicina, Enfermagem e Nutrição. Diário Oficial da União 3 out 2001. [acesso em 05 fev 2010]. Disponível em: < http:// portal.mec.gov.br/dmdocuments/ces1133.pdf $>$.

7. Fernandes JD, Xavier IM, Ceribelli MIPF, Bianco MHC, Maeda D, Rodrigues MVC. Diretrizes curriculares e estratégias para a implantação de uma nova proposta pedagógica. Rev Esc Enferm USP 2005;39(4):443-9.

8. SAES, SG. Estudo bibliométrico das publicações em economia da saúde, no Brasil, 1989-1998. São Paulo. Dissertação [Mestrado em Administração de Serviços de Saúde]Universidade de São Paulo; 2000.

9. Triviños, ANS. Introdução à Pesquisa em Ciências Sociais. São Paulo: Atlas; 2008.

10. Reibnitz KS, Prado ML. Inovação e educação em enfermagem. Florianópolis: Cidade Futura; 2006. 
11. Witt RR. Competências dos profissionais de saúde no referencial das funções essenciais de saúde pública: contribuições para a construção de projetos pedagógicos na enfermagem. Rev Bras Enferm 2003;56(4):433-8.

12. Ministério da Saúde (Brasil), Programa Nacional de Reorientação da Formação Profissional em Saúde - Pró-Saúde: objetivos, implementação e desenvolvimento potencial. [monografia na internet]. Brasília; Ministério de Saúde; 2007 [acesso em 08 fev 2010]. Disponível em:
< http://www.prosaude.org/rel/pro_saude1.pdf > .

13. Santos SSC. Perfil de egresso de curso de enfermagem nas Diretrizes Curriculares Nacionais: uma aproximação. Rev Bras Enferm 2006;59(2):217-21.

14. Backes VMS, Canever BP, Ferraz F, Lino MM, Prado ML, Reibnitz KS. Grupos de pesquisa de educação em enfermagem da Região Sul do Brasil. Rev Gaúch Enferm 2009;30(2):249-56. 